\title{
Research on the Application of Composite Materials in Building Reinforcement Engineering
}

\author{
Mostafa Yadama* \\ Washington State Univ, Dept Civil \& Environm Engn, Pullman, WA 99164 USA \\ *Corresponding author: Mostafa Yadama, E-mail: 13091011022@163.com
}

DOI: $10.37155 / 2717-526 \mathrm{X}-0302-4$

\begin{abstract}
The paper analyzes the development process and advantages of composite materials and finds that the use of composite materials in building reinforcement projects will have good application results. Then through experimental research, the application effects of glass fiber composite materials, carbon fiber composite materials and carbon fiber / glass fiber composite materials in building reinforcement engineering are analyzed. The experimental results show that: carbon fiber / glass fiber composite materials have better reinforcement effect; compared with carbon fiber composite materials, the cost of materials is lower.

Keywords: Composite materials; Reinforcement; Glass fiber; Carbon fiber; Application
\end{abstract}

Composite materials are compositions of different materials that are treated to form a new material that combines the advantages of several materials ${ }^{[1]}$. The application of composite materials will be of great importance due to the large number of building projects that require reinforcement. The most used composite material today is the fibre composite material, as this material has many advantages. This paper will examine how glass fibre, carbon fibre and the combination of the two will be used in building reinforcement projects.

\section{The Development Process of Composite Materials}

With the continuous development of technology and the need to meet the needs of society, various new materials have been created in the field of construction engineering. As a new and widely used material in today's society, composite materials play an important role in the field of construction and engineering. There are three main types of composite materials used in reinforcement work, namely carbon fibre, aramid fibre and glass fibre ${ }^{[2]}$. Fibre composites are mainly composed of resins and fibres, which are mixed in a certain ratio to form unique structural materials with different functions ${ }^{[3]}$. The application of composite materials to construction projects is bound to play a good role in reinforcement because of the unique advantages they offer and therefore their increasing status in construction projects.

Composites were already in use in civil construction between 1950 and 1960. In 1961, carbon fiber composites were added to the spires of Britain's churches, at a time when the technology for applying composites was still improving and its range of applications was expanding. By 1970, composite applications were able to be used in artificial flyovers. As materials and technology continue to mature, glass fibre composites are beginning to 
replace the use of steel reinforcement, which shows that the application of glass fibre composites is better than steel. People are gradually paying attention to the role of composite materials in construction engineering. In 1982, carbon fibre composites were used in highway construction in Beijing, China which leads to a further increase in the load-bearing capacity of roads ${ }^{[4]}$. The main role of composite materials is to provide reinforcement, with the continuous development of technology, composite materials can be used to reinforce building works in an earthquake environment, thus increasing the resistance to earthquakes ${ }^{[5]}$. Composites are becoming a material with a wide range of applications.

\section{Advantages of Composite Materials}

The composite materials used in construction are mainly composed of fibres and resins, where the role of the fibres is to increase the strength of the composite ${ }^{[6]}$. The application of composite materials to structures increases their tensile strength and offers significant advantages over steel reinforcement. Figure 1 shows the comparison of the tensile strength of composites and other materials. From Figure 1, it can be seen that composites generally have greater tensile strength than other materials, and among the composites, the tensile strength of carbon fibre composites is greater than that of aramid fibre composites than glass fibre composites. In addition, composite materials have many other advantages, such as good corrosion resistance, being able to resist the corrosion of acids and bases and other substances; lightweight, will not add to the burden of the building structure; simple construction

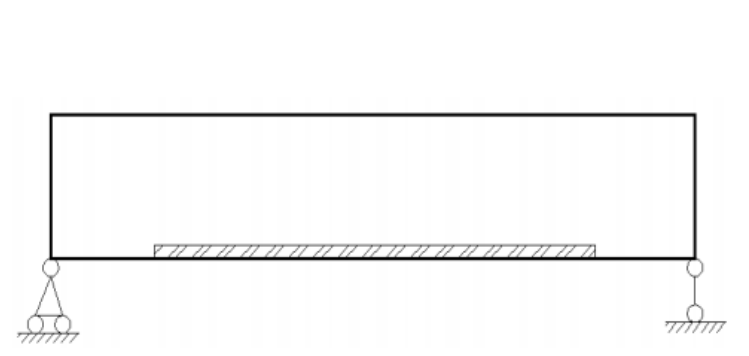

Figure 2. Schematic Diagram of Strengthening Method of Embedded Building Structure

The main advantages of using the embedded reinforcement method are shown below:

By placing the composite material into the reinforcing member, when the member is impacted by external forces, it will not directly impact the process, short construction period, can save costs; also has fatigue resistance, durability and so on. These advantages have allowed composite materials to gradually replace the use of steel reinforcement, and their application has become more widespread.

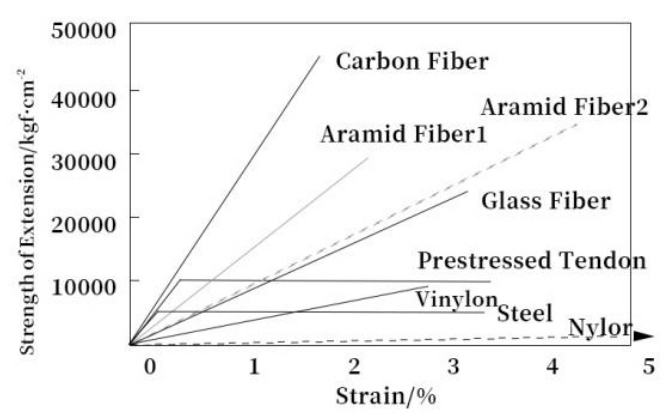

Figure 1. Comparison of Tensile Strength of Composite Materials and Other Materials

\section{Approaches to Composite Materials in Building Reinforcement Engineering}

\subsection{Embedded Reinforcement Method}

There are many methods of reinforcing building structures with composite materials, so the embedded reinforcement method has been proposed ${ }^{[7]}$. The embedded reinforcement method involves embedding the composite material inside the building structure by first cutting shallow trenches into the surface of the building structure and then placing the composite material into them so that it becomes integral to the building structure. Composite materials have excellent mechanical properties and can share external forces with the building structure, thus increasing the shear capacity or bending resistance of the structure. Figure 2 shows the construction method using embedded reinforcement.

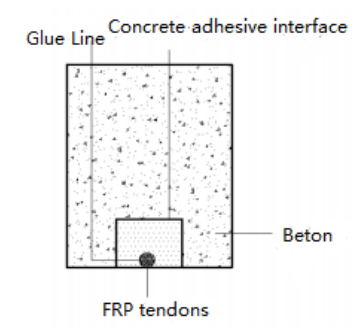

composite material, thus reducing the damage to the composite material. By embedding the composite material into the structure so that the two become a single unit, the reinforcement is better served. Inset reinforcement increases the area of the composite 
material to be utilised, which can lead to wastefulness. However, its construction is relatively simple, does not require a lot of human and material resources, and the construction area is small, thus saving the construction costs of building reinforcement.

The use of embedded reinforcement also requires a certain construction process to be followed, which can reduce the effectiveness of composite reinforcement when there are problems with the construction process. The construction steps are shown below:

(1) Slotting is carried out in the structure and the dimensions of the slots are based on the design requirements for the reinforcement of the building elements. The size of the slotting cannot be designed arbitrarily and needs to be derived from a series of calculations.

(2) After the grooving is completed, the grooves will be filled with dust and other impurities, which need to be cleaned out to avoid affecting the bonding effect of the composite material.

(3) The adhesive is then added to the trough, stopping when the thickness of the adhesive is half the height of the trough.

(4) After stopping the addition of adhesive, the composite is placed in the grooves and gentle pressure is applied to it, which will continue to add adhesive to the grooves until it is full.

(5)Finally wait for the adhesive to cure and treat the surface of the building structure once curing is complete.

\subsection{External Reinforcement Method}

The external reinforcement method involves the use of an adhesive to attach the composite material to the external surface of the building structure ${ }^{[7]}$. Figure 3 is a schematic diagram of the use of this method. The main advantage of using external reinforcement is that it is very convenient and can be carried out quickly. Due to the composite material having good corrosion protection properties, it is bonded to the outside of the structure to protect it from corrosion. Regular maintenance of the structure is therefore not required and maintenance costs are saved. The construction process using external reinforcement is relatively simple and consists of five main construction processes. Firstly, the base of the reinforcement is treated, that is, the surface is cleaned of impurities. Secondly, the primer is applied. Thirdly, levelling the surface of the reinforced structure helps to bond the composite evenly to the surface of the structure. Fourthly, the composite material is bonded, and in order to play a protective role for the composite material. The last step will be plastering or spraying fireproof paint on its surface.

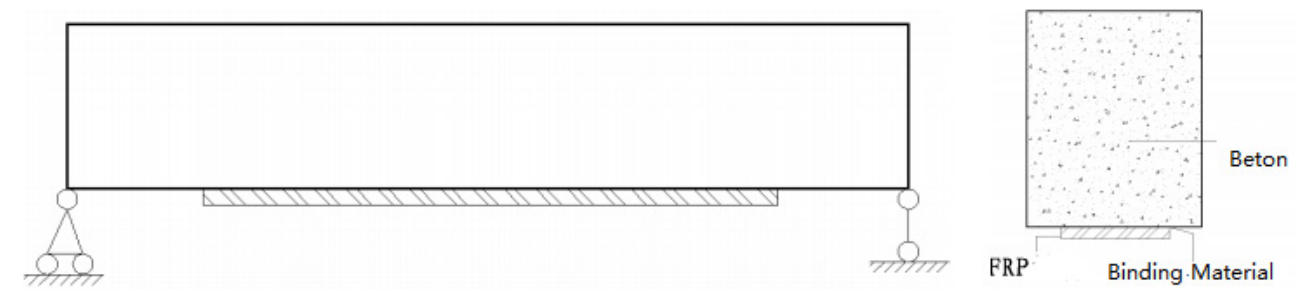

Figure 3. Schematic Diagram of the External Reinforcement Method

\section{Application of Composite Materials in Building Reinforcement Engineering}

There are three main types of composite materials used in building reinforcement work, namely carbon fibre, aramid fibre and glass fibre. The most used today is carbon fibre, as its properties are more dominant. The application of composite materials to building reinforcement projects requires experimental research as to which composite material has better performance. This article will analyse the effects of three materials - carbon fibre composites, glass fibre composites and carbon fibre/glass composites - in the application of building reinforcement.

\subsection{Experimental Section}

\subsubsection{Experimental materials and equipment}

The main materials required for the experiment: 14 short columns of plain concrete set aside for 5 years with a size of $15 \mathrm{~cm} \times 15 \mathrm{~cm} \times 45 \mathrm{~cm}$; carbon fibre composite; glass fibre composite; epoxy resin adhesive, etc.

The main equipment required for the experiment: press machine. 
Table 1. Parameters of Carbon Fiber Composite Materials and Glass Fiber Composite Materials

\begin{tabular}{|c|c|c|c|c|c|}
\hline $\begin{array}{c}\text { Types of composite } \\
\text { materials }\end{array}$ & $\begin{array}{c}\text { Tensile strength } \\
\text { limit(N) }\end{array}$ & $\begin{array}{c}\text { Elasticity } \\
\text { modulus(MPa })\end{array}$ & $\begin{array}{c}\text { Elongation at } \\
\text { break }(\%)\end{array}$ & Density & Price $\left(\mathrm{RMB} / \mathrm{m}^{2}\right)$ \\
\hline Carbon fibre & 498 & 252000 & 1.3 & - & 300 \\
\hline Glass fibre & 279 & 71000 & 2.3 & 3 Beam $/ 10 \mathrm{~mm}$ & 3.8 \\
\hline
\end{tabular}

\subsubsection{Experimental samples and grouping}

The 14 short columns were divided into four groups as shown in Table 2. The first group consists of short columns of plain concrete containing 3 pieces, denoted by compliance with $\mathrm{P}$. The second group consists of short columns of glass fibre composites containing 3 pieces, denoted by compliance with GF. The third group consists of short columns of carbon fibre composites containing 4 pieces, denoted by compliance with $\mathrm{CF}$. The fourth group consists of short columns of carbon fibre/glass fibre composites containing 4 pieces, denoted by compliance with $\mathrm{CF} / \mathrm{GF}$.

Table 2. Sample Grouping and Failure Load

\begin{tabular}{|c|c|c|c|c|c|c|}
\hline Group indication & 1 & 2 & 3 & 4 & Mean value & $\begin{array}{l}\text { Relative } \\
\text { intensity }\end{array}$ \\
\hline $\mathrm{P}$ & 540 & 536 & 585 & & 553.7 & 1. 00 \\
\hline GF & 556 & 488 & 618 & & 554 & 1. 00 \\
\hline $\mathrm{CF}$ & 602 & 608 & 606 & 602 & 604.5 & 1. 09 \\
\hline $\mathrm{CF} / \mathrm{GF}$ & 656 & 624 & 635 & 610 & 631.3 & 1. 14 \\
\hline
\end{tabular}

\subsubsection{Reinforcement of experimental samples}

In this article, the strengthening of the building structure is carried out by means of an external application of reinforcement. For the GF group, a glass fibre cloth is used, which is $10 \mathrm{~cm}$ wide and is bonded to the short posts using a wrap-around method with a lap width of $2 \mathrm{~cm}$. The samples in the CF group were made using strips of carbon fibre bonded to short posts at $1 \mathrm{~cm}$ intervals. The procedure for reinforcing the samples in the $\mathrm{CF} / \mathrm{GF}$ group was to first bond the carbon fibre strips to the short columns in $2 \mathrm{~cm}$ intervals and then to bond the glass fibre composite to its surface in a wrap-around fashion.

\subsection{Experimental Results and Analysis}

\subsubsection{Analysis of the failure modes of short columns reinforced with different composite materials}

The press machine was used to load each sample and when the sample failed, the failure pattern was shown in Figure 4. Throughout the experiment, the changes that occur in each sample, including its fracture and ultimate load, need to be documented, with the results shown below:

\section{(1) P Sample}

When the load is increased to $80 \%$ of its ultimate load, a fracture is heard in the short column and tiny longitudinal cracks can be seen in the middle of the short column, when the load continues to be increased, cracks also rapidly appear on the sides of the short column and then the short column is crushed.

\section{(2) GF Sample}

When the load is increased to $75 \%$ of its ultimate load, a fracture is heard in the short column, which can be analysed as a longitudinal fracture in the interior of the short column. The load then continues to be added and when its ultimate load is reached, the surface of the short column is cracked and the glass fibre composite is then pulled off and the short column is then crushed.

(3) CF Sample

When the load was increased to $90 \%$ of its ultimate load, no cracks were heard or seen in the short column, so the load was continued and loaded to its ultimate load and it was found that the carbon fibre composite material in the middle part of the short column was pulled off and at the same time the short column was crushed.

\section{(4) $\mathrm{CF} / \mathrm{GF}$ Sample}

When the load was increased to $95 \%$ of its ultimate load, a fracture was heard in the short column, but no fracture was observed in the glass fibre composite on its surface.

In combination with Figure 4, it is concluded that the short columns with composite reinforced 
concrete show finer cracks on the same face compared to the $\mathrm{P}$ sample. $\mathrm{CF} / \mathrm{GF}$ samples have more cracks on the surface than CF samples than GF samples than $P$ samples. And the load-carrying capacity of each sample is shown in Table 2 so. The measured load-strain curves for the different samples are shown in Figure 5.
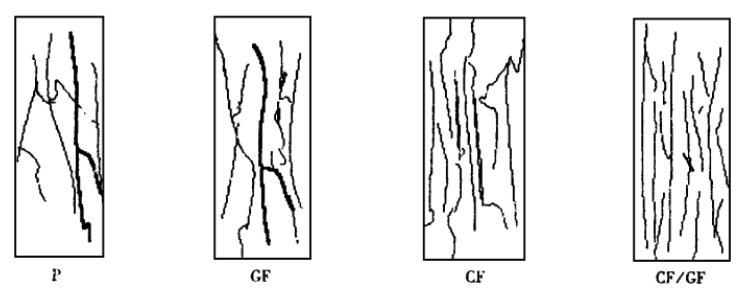

Figure 4. Schematic Diagram of Failure Modes of Short Columns Reinforced with Different Composite Materials

\subsubsection{Reinforcement mechanism analysis}

The analysis shows that the plasticity and ultimate load capacities of the other three concrete columns have been increased compared to the plain concrete columns. The ultimate load capacity of the columns strengthened with glass fibre composites has increased but not significantly, while the increase in their plasticity is very significant. The reinforcement of columns with carbon fibre composites shows an increasing trend exactly opposite to that of columns reinforced with glass fibre composites, i.e. the ultimate load capacity increases very significantly, while the plasticity increase is not significant. The reinforcement of columns with carbon fibre/glass fibre composites improves the deficiencies of both materials, i.e. it increases the plasticity and load capacity very significantly.

The reasons for this phenomenon are shown below:

As can be seen from Table 1, the modulus of elasticity of the glass fibre composite is relatively small and although the material is bonded to the column in a wrap-around fashion, the lateral restraining force is so small as to be almost negligible, so that the column can be considered uniaxially compressed in the precompression period. When a crack occurs in a column the stress in the glass fibre is increased, and because the crack is wide the three-way stress state is not produced, combined with a reduction in the load-bearing capacity of the column, so its increase in load bearing-capacity is not obvious in columns reinforced with glass fibre composites. The increase in plasticity is more pronounced as the glass fibre composite will restrain the column from cracking and will therefore exhibit a certain amount of plasticity.

The modulus of elasticity of carbon fibre composites is very large, even larger than ordinary steel reinforcement, as can be seen from Table 1. In addition, carbon fibre is more flexible and will be flatter and better bonded when using adhesives, which will result in a three-dimensional stress, i.e. an obvious increase in column load bearing-capacity. In addition, the ductility of carbon fibre composites is small, so improving their plasticity will not appear obvious.

Carbon fibre/glass fibre composites for structural column reinforcement of buildings can combine the advantages of both. At the beginning of the loading, because the carbon fibre composite was able to restrain the column, a triaxially compressed state was formed with approximately twice the average transverse strain of the CF sample. The reason for the significant increase in stress is that the high elongation of the glass fibre can take up the low elongation of the carbon fibre, i.e. by combining the two composites, the elongation becomes higher and the stress increases significantly ${ }^{[8]}$. As can be seen from Table 1 carbon fibre composites are quite expensive and glass fibre composites are relatively inexpensive. Compared to the use of carbon fibre composites for strengthening members, reinforcement with carbon fibre/glass fibre composites can save on the use of carbon fibre, the total reinforcement price is $77.3 \%$ of that of carbon fibre composite reinforcement, and the ultimate strain and load capacity are higher than that of carbon fibre reinforcement. In summary, the use of carbon fibre/ glass fibre composites in building reinforcement works is more effective and saves the cost of reinforcement.

\section{Conclusion}

The use of composite materials in building reinforcement projects can achieve better results. The plasticity and load-bearing capacity of carbon fibre/glass fibre composite reinforcement is greater than that of the other two, and carbon fibre/glass fibre composites are more cost-effective. Nowadays, 
composite materials play an important role as the main material for reinforcement works. With the development of technology, composite materials will be constantly innovated and the quality of building reinforcement works will be better in the future.

\section{References}

[1] J. Dong, Q. Wang, M. Hou \& D. He. Research on Bearing Capacity of Concrete Beams Shear Reinforced by FRP Sheets. Advanced Engineering Sciences, 2012, 44 (3): 71-77.

[2] X. Wang. Aseismatic Research of Masonry Walls Reinforced by Fiber Reinforced Plastic. Tongji University, 2003.

[3] D. Xue \& P. Hu. Fibrous Composite in Infrastructure Engineering-Opportunity and Challenge in 21st
Centary. Hi-tech Fiber \& Application, 25(2): 10-13.

[4] W. Liao. Research on Carbon Fibre Reinforcement Technology for Bridge Structures. Chang'an University, 2002.

[5] Q. Xu. The Application and Study of FRP in the Earthquake Resistant Structures. World Earthquake Engineering, 2007, 23(3): 168-170.

[6] X. Ma. Several Important Problems of Reinforced Concrete by Fiber Composite Materials. Shantou University, 2005.

[7] Y. Wu. Anti-seismic Strengthening Design of An Apartment House. Earthquake Resistant Engineering and Retrofitting, 2009(02): 85-88.

[8] S. Qiao. Mesoscopic Mechanical Properties of Composites. Northwestern Polytechnical University Press, 1997. 